\section{BMJ Open \\ Respiratory Research}

\title{
Antibiotics for COPD exacerbations: does drug or duration matter? A primary care database analysis
}

\author{
Marie Stolbrink, ${ }^{\oplus 1}$ Laura J Bonnett, ${ }^{2}$ John D Blakey ${ }^{3,4}$
}

\begin{abstract}
To cite: Stolbrink M, Bonnett LJ, Blakey JD. Antibiotics for COPD exacerbations: does drug or duration matter? A primary care database analysis. BMJ Open Resp Res 2019;6:e000458. doi:10.1136/ bmjresp-2019-000458
\end{abstract}

- Additional material is published online only. To view, please visit the journal online (http://dx.doi.org/10. 1136/bmjresp-2019-000458)

Received 16 June 2019 Revised 7 August 2019 Accepted 10 August 2019

Check for updates

(c) Author(s) (or their employer(s)) 2019. Re-use permitted under CC BY. Published by BMJ.

${ }^{1}$ Institute of Infection and Global Health, University of Liverpool, Liverpool, UK

${ }^{2}$ Department of Biostatistics, University of Liverpool, Liverpool, UK

${ }^{3}$ Respiratory Medicine, Sir Charles Gairdner Hospital, Perth, Western Australia, Australia

${ }^{4}$ Medical School, Curtin University, Perth, Western Australia, Australia

Correspondence to Dr Marie Stolbrink; mstolbrink@doctors.org.uk

\section{ABSTRACT}

Introduction Antibiotics are routinely given to people with chronic obstructive pulmonary disease (COPD) presenting with lower respiratory tract infection (LRTI) symptoms in primary care. Population prescribing habits and their consequences have not been well-described.

Methods We conducted a retrospective analysis of antibiotic prescriptions for non-pneumonic exacerbations of COPD from 2010 to 2015 using the UK primary care Optimum Patient Care Research Database. As a proxy of initial treatment failure, second antibiotic prescriptions for LRTI or all indications within 14 days were the primary and secondary outcomes, respectively. We derived a model for repeat courses using univariable and multivariable logistic regression analysis.

Results A total of $8.4 \%$ of the 9042 incident events received further antibiotics for LRTI, $15.5 \%$ further courses for any indication. Amoxicillin and doxycycline were the most common index and second-line drugs, respectively $(58.7 \%$ and $28.7 \%)$, mostly given for 7 days. Index drugs other than amoxicillin, cardiovascular disease, pneumococcal vaccination and more primary care consultations were statistically significantly associated with repeat prescriptions for $\mathrm{LRTI}(\mathrm{p}<0.05)$. The $\mathrm{ORs}$ and 95\% Cls were: OR $1.28,95 \%$ Cl 1.10 to 1.49 ; OR 1.37 , $95 \% \mathrm{Cl} 1.13$ to 1.66 ; OR $1.33,95 \% \mathrm{Cl} 1.14$ to 1.55 and OR $1.05,95 \%$ Cl 1.02 to 1.07 , respectively. Index duration, inhaled steroid use and exacerbation frequency were not statistically significant. The derived model had an area under the curve of $0.61,95 \% \mathrm{Cl} 0.59$ to 0.63 .

Discussion The prescription of multiple antibiotic courses for COPD exacerbations was relatively common-one in twelve patients receiving antibiotics for LRTI had a further course within 2 weeks. The findings support the current preference for amoxicillin as index drug within the limitations of this observational study. Further clinical trials to determine best practice in this common clinical situation appear required.

\section{INTRODUCTION}

Lower respiratory tract infections (LRTIs) are globally the most common infectious cause of morbidity. ${ }^{1}$ Despite this prevalence, observed duration of antibiotic treatment for LRTI varies greatly, and there is disagreement between guidelines on the optimal duration. $^{2}$ Effective first-line treatment for non-pneumonic LRTI in chronic obstructive

\section{Key messages \\ A substantial proportion of COPD patients received a second course of antibiotics within fourteen days of the index prescription. \\ - Amoxicillin was prescribed most commonly as the index drug and was associated with fewer repeat antibiotic prescriptions. \\ - Shorter index courses were not associated with more repeat prescriptions.}

pulmonary disease (COPD) patients ('infective exacerbations') is an area of particular uncertainty.

COPD is a common cause of disability, and estimated to become the third leading cause of death worldwide in 2030..$^{3-5}$ Exacerbations form a large part of the disease burden and can lead to a cough with discoloured phlegm irrespective of causation. Over $£ 250$ million is spent on treating COPD exacerbations annually in the UK, and recurrent exacerbations are associated with increased morbidity and mortality. ${ }^{6}$

Up to half of all COPD exacerbations are thought to be caused by bacteria, the remainder by viruses or environmental irritants. ${ }^{7-10}$ The most common pathogens are Haemophilus influenzae, Moraxella catarrhalis and Streptococcus pneumoniae. ${ }^{6}$ Initial studies suggested that the administration of antibiotics was associated with a lower risk of symptom persistence. ${ }^{11}$ However, a Cochrane review concluded that a statistically significant improvement in treatment failure rate was only seen in severe exacerbations, with more adverse events in the antibiotic group. ${ }^{7}$ Hence, the European Respiratory Society/American Thoracic Society and international guidelines advise, based on moderate evidence, the prescription of antibiotics for ambulatory patients 'if clinically indicated'. ${ }^{12} 13$ However, our understanding of the success of real-life prescribing practices is limited. 
The risk of treatment failure without antibiotics needs to be balanced with antimicrobial resistance, contributed to by inappropriate and non-evidence based prescribing, and adverse drug effects, including Clostridium difficile infection. ${ }^{14-16}$ Primary care is an optimal environment to improve antibiotic use since $74 \%$ of all UK antibiotics are prescribed here and around three-quarters of patients presenting in primary care with an acute COPD exacerbation receive antibiotics. ${ }^{17-19}$ Moreover, a European-wide COPD audit of hospitalised patients demonstrated that antibiotics were more likely to be continued during admissions and after discharge if they had already been received in primary care. ${ }^{20}$

Guidelines on antibiotics for COPD exacerbations are not specific and based only on moderate evidence. The National Institute of Health and Care Excellence guidelines for the study period suggest using an aminopenicillin, macrolide or tetracycline but give no indication on duration. ${ }^{21}$ The Global Initiative for Chronic Obstructive Lung Disease advises 5-7 days duration but no antibiotic class. ${ }^{13}$ A recent meta-analysis presented dirithromycin, ofloxacin and ciprofloxacin as having the best cure and side-effect profiles, yet these are not used routinely in clinical practice. ${ }^{22}$

In this study, we characterised patterns of antibiotic prescribing for COPD exacerbations via a retrospective observational analysis of primary care data from 2010 to 2015. We explored the factors associated with the risk of further antibiotic prescription, which may form the basis for future comparative interventional studies, such as clinical trials comparing different antibiotic durations, or first-line drugs in specific patient groups.

\section{METHODS}

We carried out a cross-sectional database study drawing on retrospective, electronic medical records from the Optimum Patient Care Research Database (OPCRD). Individuals were included if they had an active diagnosis of COPD during the study period, demonstrated by their primary care coding.

We included COPD patients who received at least one antibiotic prescription with an LRTI read code from 01 April 2010 to 01 April 2015. LRTI codes included those for chest infection and bronchitis. We analysed only the first event for each individual to exclude repeated measurements from the same patient. Primary outcome was a new antibiotic prescription with an LRTI code within 14 days of the index prescription. Secondary outcome was further antibiotic prescription within 14 days for any indication. We excluded cases with a coded diagnosis of pneumonia, other chronic respiratory diseases, such as asthma, people younger than 16 years and those whose index antibiotic course was either not specified or was longer than 28 days.

\section{Data source}

The OPCRD comprised data extracted through the Optimum Patient Care Clinical Service Evaluation (http://optimumpatientcare.org/opcrd/). The OPCRD is a quality-controlled, primary care research database focussing on respiratory disease. It contained anonymous, routinely recorded electronic medical records data from over 525 UK general practices.

\section{Statistical analysis}

Data were analysed using SPSS V.22. We examined multiple factors to assess the risk of repeat antibiotic prescription for LRTI or any indication, including demographics, smoking status, comorbidities, COPD disease control, including medication and interactions with secondary care, and index antibiotic duration and class.

Individual factors were first assessed using univariable analysis. Univariably, mean differences in continuous variables were analysed via t-tests, while ORs for binary variables were analysed via logistic regression. Multivariable models were built using logistic regression with backwards selection. Summary statistics, $\chi^{2}$ and Student $t$ tests were presented as appropriate for each variable, based on type and distribution of data. Statistically significant results were defined as $\mathrm{p}<0.10$ for univariable analysis (to show trends) and $\mathrm{p}<0.05$ for multivariable analysis. Collinear associations between clinically plausible-related predictors were assessed using Pearson's correlation coefficients. Factors were included in the multivariable model based on clinical plausibility. Adjusted ORs and CIs were presented where appropriate. Visual inspection of the functional form of each continuous variable suggested that no transformation was required. Multivariable models were derived via backwards parsimonious logistic regression, including linear regression for mean differences, and the resulting models were tested for goodness of fit.

\section{RESULTS}

\section{Demographics}

There were 22003 unique prescriptions for LRTI in adult COPD patients between 01 January 2010 and 31 December 2015 in the OPCRD. The mean age was 71 years and $48.2 \%$ were women. A total of $45.6 \%$ were ex-smokers and $42.4 \%$ were current smokers, $4.9 \%$ were never-smokers (smoking status was missing in $7.1 \%)$. Most patients were from the Midlands and East England $(58.9 \%)$. The most common LRTI codes were for 'chest infection' (44.3\%), 'acute exacerbation of chronic obstructive airways disease' $(28.1 \%)$ and 'lower respiratory tract infection' (17.3\%). Table 1 describes the baseline demographics and all variables included in the univariable analysis.

A total of $9042(41 \%)$ patients had a documented index antibiotic duration for LRTI and were included in the analysis (figure 1). Individuals receiving antibiotics for an uncertain duration (eg, only number of tablets documented) were excluded, as were a small number of individuals with treatment durations over 28 days. Most index courses were prescribed for 7 days $(75.7 \%)$, 
Table 1 Baseline demographics of all individuals included in the study

\begin{tabular}{|l|l|}
\hline Variable & $\begin{array}{l}\text { All patients }(\mathbf{n}=22003) \\
\text { Number }(\%) \text { unless } \\
\text { otherwise indicated }\end{array}$ \\
\hline Female sex & $10605(48.2)$ \\
\hline Age (years), mean \pm SD & $70.83 \pm 10.9$ \\
\hline BMl $\left(\mathrm{kg} / \mathrm{m}^{2}\right)$, mean \pm SD & $27.2 \pm 6.1$ \\
\hline Smoking status & \\
\hline Non-smoker & $1081(4.9)$ \\
\hline Current smoker & $9326(42.4)$ \\
\hline Ex-smoker & $10033(45.6)$ \\
\hline Missing & $1563(7.1)$ \\
\hline
\end{tabular}

\section{Primary and secondary care} consultations

Number of respiratory consultations in primary care ${ }^{\star}$

1
2
3
$\geq 4$

Number of all consultations in primary
care $^{\star}$, mean $\pm S D$

Number who had at least one inpatient 326 (1.4) admission for respiratory code*

\begin{tabular}{|c|c|}
\hline \multicolumn{2}{|l|}{ Exacerbations* } \\
\hline 0 & $10203(46.4)$ \\
\hline 1 & $6831(31.0)$ \\
\hline 2 & $2729(12.4)$ \\
\hline$\geq 3$ & $2240(10.2)$ \\
\hline \multicolumn{2}{|l|}{ Lung function } \\
\hline FEV1 (L), mean \pm SD & $1.43 \pm 0.61$ \\
\hline FEV1/FVC ratio, mean \pm SD & $0.59 \pm 0.3$ \\
\hline \multicolumn{2}{|l|}{ COPD treatment } \\
\hline $\begin{array}{l}\text { Number of SABA prescriptions } \\
\text { mean } \pm \text { SD }\end{array}$ & $4.78 \pm 5.3$ \\
\hline Number using ICS & $12925(58.7)$ \\
\hline $\begin{array}{l}\text { Number of LAMA prescriptions*, } \\
\text { mean } \pm \text { SD }\end{array}$ & $3.02 \pm 4.5$ \\
\hline Number of LABA inhalers ${ }^{*}$, mean \pm SD & $0.41 \pm 2.0$ \\
\hline No treatment & $2718(12.4)$ \\
\hline \multicolumn{2}{|l|}{ Vaccinations } \\
\hline Influenza vaccination ever & $13894(63.1)$ \\
\hline Pneumococcal vaccination ever & $6860(31.2)$ \\
\hline $\begin{array}{l}\text { Blood eosinophil count closest to index } \\
\text { antibiotic prescription, mean } \pm S D\end{array}$ & $0.31 \pm 0.5$ \\
\hline \multicolumn{2}{|l|}{ Recorded comorbidity } \\
\hline Diabetes & $3286(14.9)$ \\
\hline Anxiety/depression & $1811(8.2)$ \\
\hline Cardiovascular disease & 2407 (10.9) \\
\hline \multicolumn{2}{|l|}{ Concurrent medications } \\
\hline Paracetamol prescription* & $10554(48.0)$ \\
\hline
\end{tabular}

Table 1 Continued

\begin{tabular}{ll}
\hline Variable & $\begin{array}{l}\text { All patients }(\mathrm{n}=22003) \\
\text { Number }(\%) \text { unless } \\
\text { otherwise indicated }\end{array}$ \\
\hline Location & \\
\hline London & $86(0.4)$ \\
Midlands and East & $12965(58.9)$ \\
North & $4577(20.8)$ \\
South & $32349(14.8)$ \\
Missing & $1126(5.1)$ \\
\hline
\end{tabular}

*In year prior to index prescription.

$\mathrm{BMI}$, body mass index; FEV1, forced expiratory volume in $1 \mathrm{~s}$; FVC, forced vital capacity; ICS, inhaled corticosteroid; LABA, long-acting beta-agonist; LAMA, long-acting muscarinic antagonist; SABA, shortacting beta-agonist.

$10.5 \%$ received shorter and $13.8 \%$ received longer index courses. Amoxicillin, doxycycline and clarithromycin were used most commonly $(58.7 \%, 14.0 \%$ and $11.7 \%$ respectively, see figure 2A). The median index duration was 8 days for doxycycline and 7 days for all other agents.

\section{Repeat prescriptions for LRTI}

A total of $764(8.4 \%)$ patients received a second antibiotic course for LRTI within 14 days of the index prescription. The most commonly prescribed antibiotics were doxycycline, erythromycin/clarithromycin and amoxicillin

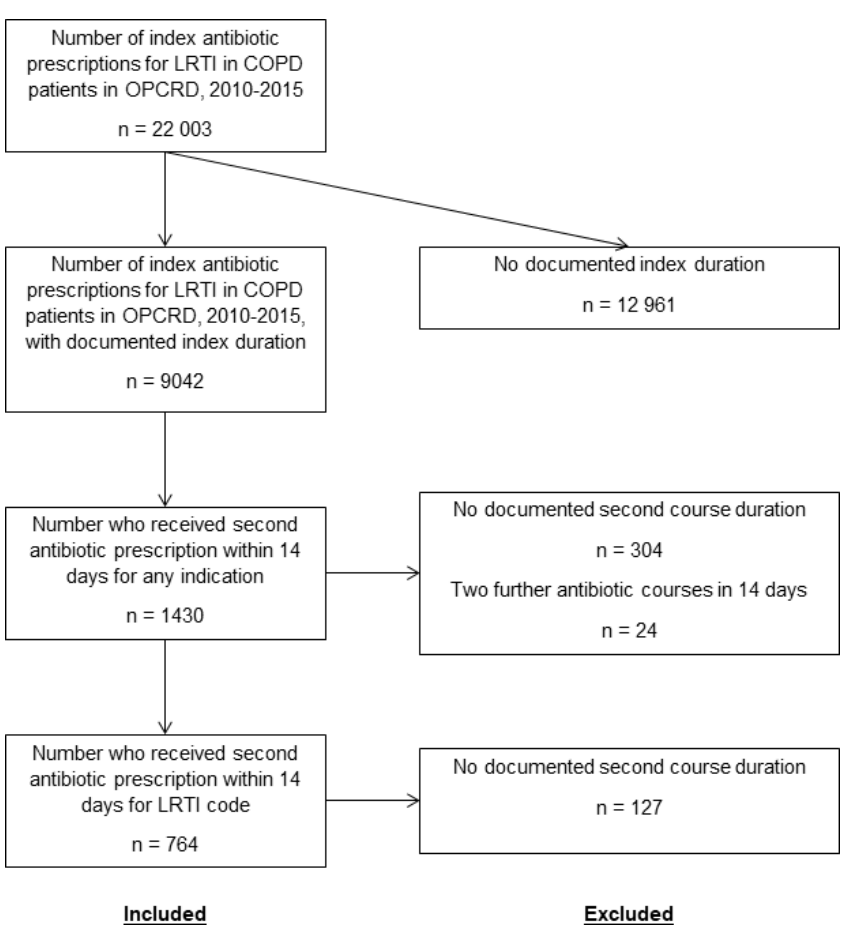

Figure 1 Flow chart of inclusion and exclusion for study analysis of antibiotic prescriptions in COPD patients in the OPCRD database, April 2010-April 2015. COPD, chronic obstructive pulmonary disease; LRTI, lower respiratory tract infection; OPCRD, Optimum Patient Care Research Database. 
A) Index antibiotic duration and drug Total number $=9042$

- 7 days $->7$ days $=<7$ days
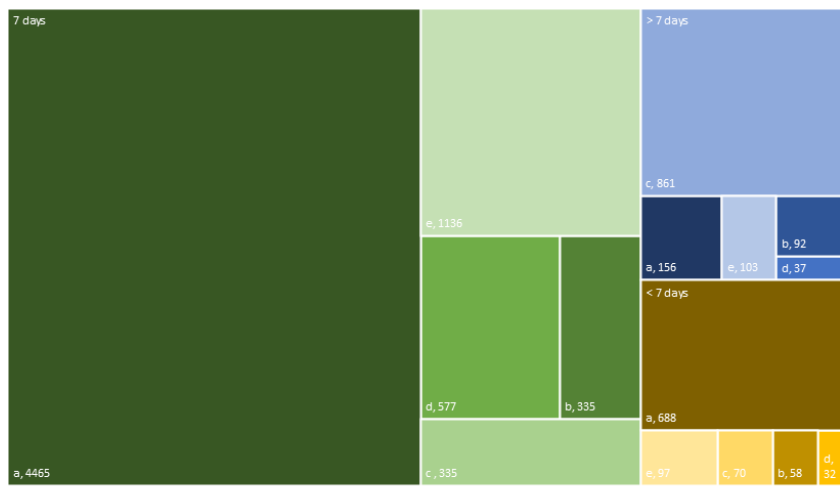

B) Repeat antibiotic duration and drug for LRTI Total number $=637$ - 7 days $\mid$ in $>7$ days $=<7$ days

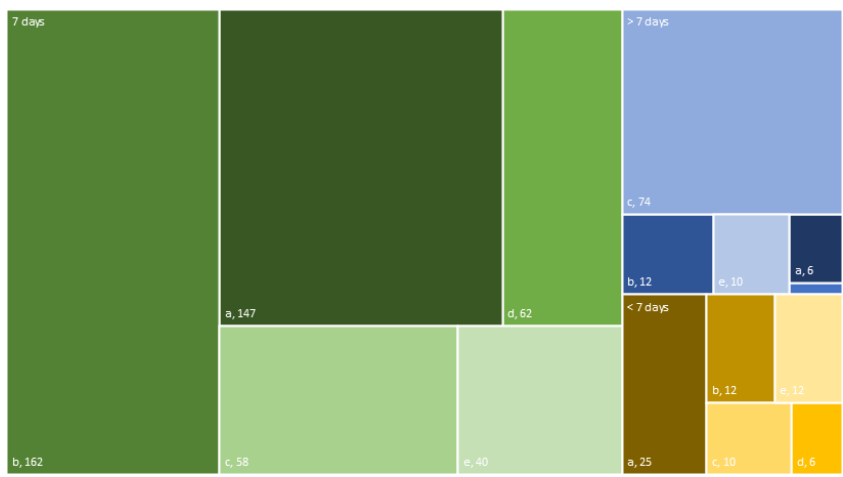

Figure 2 Treemap chart of antibiotic duration and drug of (A) index prescriptions and (B) repeat prescriptions for LRTI. Absolute numbers presented. Missing data due to missing duration (127 cases). a, amoxicillin; b, erythromycin/ clarithromycin; c, doxycycline; d, co-amoxiclav; e, other; LRTI, lower respiratory tract infection.

(28.7\%, 27.3\% and 25.8\%, respectively, see figure 2B). Most second-line prescriptions were for 7,8 or 5 days (73.5\%, 9.8\% and $8.6 \%$, respectively). The median for repeat antibiotic course duration was 7 days. A total of 127 cases had no documented second-course duration.

In the univariable analysis, those who received further antibiotics were statistically significantly older, had more comorbidities and had more severe disease as measured by higher consultation frequency, more COPD exacerbations in the past year and more COPD medications (table 2). Index drug and location were significantly associated with repeat prescription. Smoking status, FEV1 (forced expiratory volume in $1 \mathrm{~s}$ ), index duration and ICS (inhaled corticosteroids) treatment were not significantly associated with repeat prescriptions (supplementary files).

Collinearity was assessed for all statistically significant $(p<0.10)$ factors in univariable analysis. The Pearson's correlation coefficient was in excess of 0.8 between the clinically related pairs of number of oral steroid courses and exacerbation number, number of respiratory and all secondary care outpatient appointments, number of ICS inhalers and prescriptions, pure LAMA (long-acting muscarinic antagonist) prescription and inhalers, and pure LABA (long-acting beta-agonist) prescription and inhalers. We, hence, used exacerbation number, respiratory outpatient appointments, ICS, LAMA and LABA inhalers in the multivariable analysis.

The derived parsimonious multivariable model included index antibiotic, number of primary care consultations for respiratory and all complaints, number of LABA inhalers in previous year, presence of cardiovascular disease and previous pneumococcal vaccination $(\mathrm{p}<0.05$, table 2$)$. Those not receiving amoxicillin as index antibiotic, who had previously received the pneumococcal vaccine, with cardiovascular disease, more LABA inhalers or more respiratory or all primary care consultations, were at increased risk of repeat antibiotics for LRTI.

The model fitted the dichotomous outcome with a Cox-Snell $\mathrm{R}^{2}$ of 0.013 (area under the curve (AUC) 0.61, $95 \%$ CI 0.59 to 0.63$)$. Introducing interaction terms between clinically logical factors did not improve the fit of the model (supplementary files).

\section{Repeat prescriptions for all indications}

A total of 1430 patients received a second antibiotic course for any indication (15.5\%). Twenty-four of these received two courses within 14 days of index prescription and were, hence, excluded from further analysis. Doxycycline, amoxicillin and erythromycin/clarithromycin were used most $(28.9 \%, 27.0 \%$ and $26.6 \%$, respectively, supplementary figure 1) for durations of 7, 8 and 5 days (71.4\%, 9.2\% and $8.1 \%$, respectively). The antibiotics included in the 'all indications' analysis were amoxicillin, doxycycline, erythromycin, clarithromycin, co-amoxiclav, cephalexin, cefaclor and ciprofloxacin, all of which are used to treat LRTI. The median duration was 7 days. A total of 304 cases did not have a documented repeat duration.

Smoking status, number of emergency department and outpatient appointments, FEV1 as well as ICS treatment were statistically significant $(p<0.05)$ in the univariable analysis (supplementary files).

The presence of cardiovascular disease, index drug other than amoxicillin, number of all primary care consultations and exacerbations as well as number of ICS and LAMA inhalers were significantly associated with repeat antibiotic prescription in the multivariable parsimonious regression analysis $(\mathrm{p}<0.05)$. Model-checking showed a Cox-Snell $\mathrm{R}^{2}$ of 0.012 (AUC $0.58,95 \%$ CI 0.56 to 0.60 ).

\section{DISCUSSION}

\section{Summary}

In this analysis of COPD exacerbations in UK primary care, we studied over 9000 antibiotic prescriptions for LRTI over 5 years. The majority of patients received 7-day index courses and amoxicillin was the most commonly given 
Table 2 Results of statistically and clinically significant univariable and multivariable analysis for repeat antibiotic prescription for LRTI code within 14 days of index duration. Univariable analysis according to type of data

\begin{tabular}{|c|c|c|c|c|c|}
\hline \multirow[b]{2}{*}{ Variable } & \multicolumn{3}{|c|}{ Univariable analysis results } & \multicolumn{2}{|c|}{$\begin{array}{l}\text { Multiple logistic regression } \\
\text { model results }\end{array}$} \\
\hline & $\begin{array}{l}\text { OR } \\
95 \% \mathrm{Cl}\end{array}$ & $\begin{array}{l}\text { Mean difference } \\
95 \% \mathrm{Cl}\end{array}$ & $P$ value & $\begin{array}{l}\text { OR } \\
95 \% \mathrm{Cl}\end{array}$ & $P$ value \\
\hline Age & & $\begin{array}{l}-0.66 \\
-1.4 \text { to } 0.1\end{array}$ & 0.10 & & \\
\hline Location & & & $<0.01$ & & \\
\hline Midlands and East & Index & & & & \\
\hline London & $\begin{array}{l}0.59 \\
0.21 \text { to } 1.62\end{array}$ & & 0.30 & & \\
\hline North & $\begin{array}{l}0.74 \\
0.60 \text { to } 0.91\end{array}$ & & $<0.01$ & & \\
\hline South & $\begin{array}{l}0.77 \\
0.64 \text { to } 0.93\end{array}$ & & 0.01 & & \\
\hline Gastro-oesophageal reflux disease diagnosis & $\begin{array}{l}1.53 \\
1.03 \text { to } 2.27\end{array}$ & & 0.03 & & \\
\hline Cardiovascular disease diagnosis & $\begin{array}{l}1.63 \\
1.34 \text { to } 1.95\end{array}$ & & $<0.01$ & $\begin{array}{l}1.37 \\
1.13 \text { to } 1.66\end{array}$ & $<0.01$ \\
\hline Paracetamol prescription* & $\begin{array}{l}1.18 \\
1.02 \text { to } 1.37\end{array}$ & & 0.03 & & \\
\hline Pneumococcal vaccination & $\begin{array}{l}1.38 \\
1.19 \text { to } 1.60\end{array}$ & & $<0.01$ & $\begin{array}{l}1.33 \\
1.14 \text { to } 1.55\end{array}$ & $<0.01$ \\
\hline $\begin{array}{l}\text { Number of primary care respiratory } \\
\text { consultations }{ }^{*}\end{array}$ & & $\begin{array}{l}-1.05 \\
-1.29 \text { to } 0.82\end{array}$ & $<0.01$ & $\begin{array}{l}1.05 \\
1.02 \text { to } 1.07\end{array}$ & $<0.01$ \\
\hline Number of all primary care consultations* & & $\begin{array}{l}-3.16 \\
-3.89 \text { to }-2.43\end{array}$ & $<0.01$ & $\begin{array}{l}1.01 \\
1.01 \text { to } 1.02\end{array}$ & $<0.01$ \\
\hline Number of OCS* & & $\begin{array}{l}-0.10 \\
-0.20 \text { to } 0.00\end{array}$ & 0.05 & & \\
\hline Number of exacerbations* & & $\begin{array}{l}-0.10 \\
-0.20 \text { to }-0.01\end{array}$ & 0.06 & & \\
\hline FEV1 value (L) & & $\begin{array}{l}0.02 \\
-0.03 \text { to } 0.07\end{array}$ & 0.38 & & \\
\hline Count of ICS inhalers* & & $\begin{array}{l}-0.41 \\
-0.87 \text { to } 0.05\end{array}$ & 0.08 & & \\
\hline Count of LAMA prescriptions* & & $\begin{array}{l}-0.33 \\
-0.67 \text { to } 0.01\end{array}$ & 0.06 & & \\
\hline Count of LABA inhalers* & & $\begin{array}{l}-0.20 \\
-0.36 \text { to }-0.04\end{array}$ & 0.02 & $\begin{array}{l}1.03 \\
1.00 \text { to } 1.05\end{array}$ & 0.08 \\
\hline Count of LTRA prescriptions ${ }^{*}$ & & $\begin{array}{l}0.04 \\
-0.16 \text { to } 0.00\end{array}$ & 0.06 & & \\
\hline Not amoxicillin as index antibiotic & $\begin{array}{l}1.37 \\
1.18 \text { to } 1.58\end{array}$ & & $<0.01$ & $\begin{array}{l}1.28 \\
1.10 \text { to } 1.49\end{array}$ & $<0.01$ \\
\hline
\end{tabular}

Blank entries relate to variables not included in the multivariable model.

*In year prior to index prescription.

FEV1, forced expiratory volume in $1 \mathrm{~s}$; ICS, inhaled corticosteroid; LABA, long-acting beta-agonist; LAMA, long-acting muscarinic antagonist; LRTI, lower respiratory tract infection; LTRA, Leukotriene receptor antagonist;OCS, oral corticosteroid.

drug. A large proportion of antibiotic prescriptions had no explicitly recorded duration. A substantial proportion of patients $(15.5 \%)$ received further antibiotics within 14 days of the index antibiotic prescription. Over half of the repeat prescriptions within 14 days were coded for another LRTI (52.1\%). Amoxicillin as index drug was associated with fewer repeat prescriptions. Older age and some markers of COPD severity were associated with increased risk of apparent initial treatment failure.

\section{Strengths and limitations}

One of the strengths of the study is the genuine, unselected primary care population as demonstrated, for example, by $97.2 \%$ not having had a respiratory 
outpatient appointment and $46.4 \%$ not having had an exacerbation in the prior year. This contrasts with most interventional studies which have highly selected patient populations-for example, it has been estimated that only up to $7 \%$ of people treated for COPD meet inclusion criteria for randomised trials. ${ }^{23}$ Real-life data, such as this, have an important role in helping to inform real-life decision-making.

We analysed electronic health records. In the era of advancing electronic records, there is a drive to use more routinely collected data particularly in primary care research, for example, by the National Institute for Health Research or highlighted in the Salford Lung Study, to reduce burden on patients, bias and approximate real-world practice. ${ }^{24}{ }^{25}$ However, the reliance on primary care data is also this study's major limitationchiefly, the $59 \%$ of patients for whom no duration was clearly documented for their index duration of antibiotics. This reflects the true documentation practice in primary care, where coding can be challenging. ${ }^{26} \mathrm{We}$ are unable to distinguish appropriate from inappropriate antibiotic prescribing using this large primary care database, in keeping with large variation in antibiotic prescribing in primary care found in other studies that could not entirely be explained by patient characteristics. ${ }^{27}$ It is also likely that other factors, such as presence of purulent sputum or prior microbiology results, influenced decisions for repeat antibiotic prescribing. A cross-sectional primary care study in Europe, Asia and South America showed that purulent sputum and use of $\mathrm{C}$ reactive protein were the strongest predictors of initial antibiotic prescribing in COPD exacerbations. ${ }^{18}$

We examined more antibiotic courses over 5 years than an earlier primary care COPD exacerbation analysis from 2005 to $2010 .^{27}$ This study of 12609 exacerbations also showed a high prevalence of antibiotic prescribing within 7 days of presentation (66\% cases). We also reported repeat antibiotic prescribing for any indication to ensure no LRTI prescriptions were missed as not all repeat prescriptions for LRTI will have been coded appropriately.

We were limited by the potential for missing data on secondary care contacts (eg, emergency department attendances and hospital admissions) and use of other healthcare services (eg, out of hours and walk-in centres). The imperfect recording of such data is anticipated to lead to an underestimate of the true number of repeat prescriptions issued as lack of improvement increases the probability of accessing providers other than the patient's usual general practitioner. We acknowledge that some treatment failures would result in hospitalisation, and these could be incorrectly coded as if the treatment was successful (ie, no repeat course of antibiotics from primary care). However, community-treated exacerbations of COPD are far more common than hospitalisations, and most people admitted have not completed antibiotics in the community, so any effect on the analyses would be modest. ${ }^{20}$ There was no explicit coding for
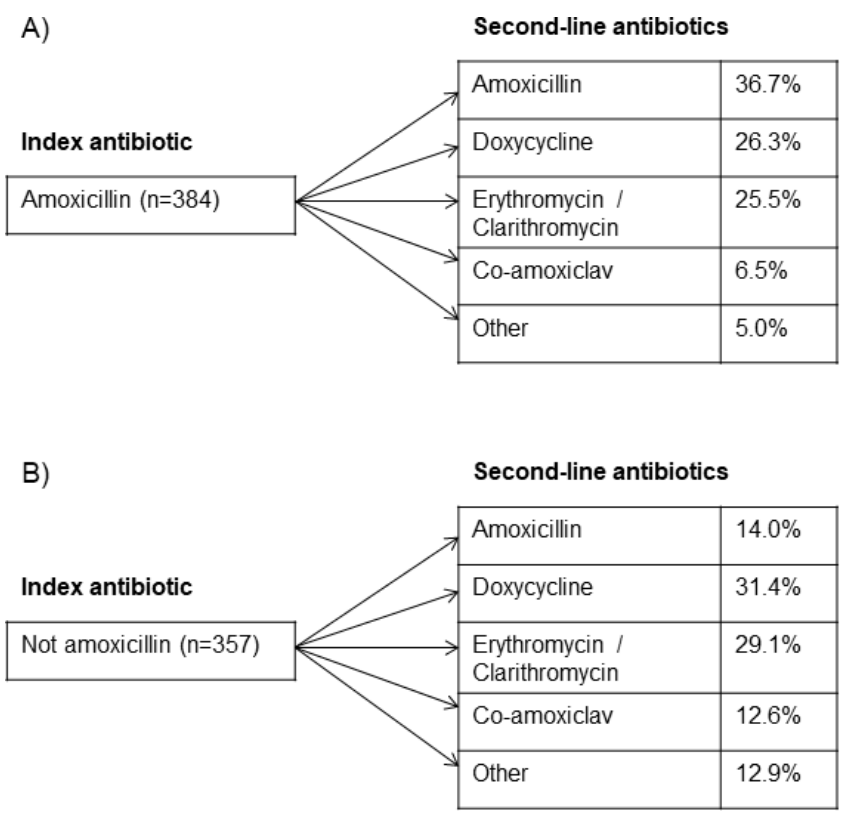

Figure 3 Second-line antibiotics used for LRTI by initial antibiotic: (A) amoxicillin and (B) not amoxicillin. Missing data due to missing drug name (23 cases). LRTI, lower respiratory tract infection.

repeat or continuous antibiotics in this data set. However, such prescriptions would have been excluded (as we did not include antibiotic courses that had a duration that was either not specified or was longer than 28 days) unless they were rotating antibiotics which are used very rarely, for example, 1 patient in over 92000 cases studied in a large retrospective primary care analysis. ${ }^{28}$ The use of long-term antibiotics in COPD patients remains rare (eg, $0.61 \%$ in the above study) and no long-term studies exist in these patients. ${ }^{28-30}$ Our study is also limited by primary care coding of COPD rather than the use of source data, such as lung function.

\section{Setting in current literature and future directions}

Durations of 7 days remained most prominent across different situations, but index duration was not significantly associated with further prescriptions. When encountering treatment failure, the decision was to change drug rather than duration (figure 3)—studies are needed to investigate whether this is the correct approach. There is limited evidence and guidance on ideal index duration for antibiotics. ${ }^{13} 21 \mathrm{~A}$ recent meta-analysis found that adverse effects in COPD patients were more prevalent when the same index antibiotic was given for more than 7 days compared with less than 7 days with no difference in clinical outcomes. ${ }^{31}$ A large retrospective analysis of UK primary care data showed that respiratory infections were responsible for the majority of antibiotics prescribed for longer than guidelines suggest, with $89 \%$ of COPD exacerbations receiving more than the recommended 5 days of treatment. ${ }^{32}$ In primary care, asthma patients 7-day courses were also associated with 
fewer repeat prescriptions. ${ }^{33}$ Our study also supports the consideration of shorter index durations, but interventional studies are needed to confirm this.

Prior pneumococcal vaccination was associated with repeat antibiotic prescription. Vaccination did not appear to be a proxy of comorbidity, age or frequency of primary care attendance given its appearance in the final multivariable model, that interaction analysis did not improve the model and there was no collinearity. In previous studies, pneumococcal vaccination has been shown to reduce vaccine-specific disease but not overall rates of LRTI ${ }^{34}$ It is, therefore, possible that these vaccinated patients may have had a true bacterial infection that was not susceptible to the common index drugs. Owing to the observational, retrospective nature of the analysed data sets, the causality of effects is difficult to ascertain. This is particularly true given a further limitation of our study: sputum culture results were not sufficiently commonly or systematically recorded to be included in the analyses.

ICS have previously shown to be associated with increased risk of pneumonia, particularly older and more severely airway constrained patients. ${ }^{35-37}$ These factors were associated with apparent treatment failure in our univariable analyses, but not in the final models.

Amoxicillin, doxycycline and erythromycin/clarithromycin were the most commonly used antibiotics. The prevalence of amoxicillin decreased from $58.7 \%$ to $25.8 \%$ in the repeat prescriptions but remained an important contributor. This may reflect practitioners attempting to address relevant pathogens, such as $M$. catarrhalis and $H$. influenzae, in the repeat courses that are usually resistant to penicillins. ${ }^{38}$ However, in contrast to this, not using amoxicillin as index antibiotic was significantly associated with the risk of repeat prescriptions for LRTI and all indications. This warrants further investigation on the pathogens of these exacerbations, particularly to differentiate true failure of antibiotic action from unacceptable side effects from the index treatment. Respiratory viruses were identified in almost $40 \%$ of patients with COPD exacerbations and only $40 \%-50 \%$ of exacerbations were thought to be caused by bacteria. ${ }^{9}{ }^{10}$ Non-bacterial exacerbations would improve irrespective of antibiotic treatment and inappropriately treated exacerbations may present as treatment failure.

\section{CONCLUSION}

Prescription of further antibiotics for LRTI occurred commonly in UK primary care COPD patients from 2010 to 2015. Our data supported usage of amoxicillin as index drug. Shorter index durations were not associated with more repeat prescriptions. Prior consultations, pneumococcal vaccine, presence of cardiovascular disease and index drug were associated with the decision to prescribe a second course. Interventional studies on the optimal drug and duration for common subsets of people with COPD in primary care are needed to properly inform guidelines for this common clinical problem.
Acknowledgements We are grateful for the support of Derek Skinner, data analyst, and Victoria Carter, Optimum Patient Care, Cambridge, UK. We are grateful to the Respiratory Effectiveness Group for support of the manuscript.

Contributors JDB and MS conceived the idea for this work and are the guarantors. MS completed the data analysis and manuscript preparation. LJB supported the statistical analysis. All the authors contributed to data interpretation and critically revised the manuscript. All the authors read and approved the final manuscript.

Funding We are grateful to the Eleanor Peel Trust for providing funding for bespoke data extraction and database creation from the OPC. MS is funded by a National Institute for Health Research (NIHR) Academic Clinical Fellowship. LJB is funded by an NIHR Post-Doctoral Fellowship (PDF-2015-08-044).

Disclaimer The views expressed in this publication are those of the authors and not necessarily those of the National Health Service, the National Institute for Health Research or the Department of Health.

Competing interests JDB reports personal fees from Novartis and Teva, personal fees and non-financial support from AstraZeneca and Boehringer Ingelheim, and non-financial support from Virginia Commonwealth University and Respiratory Effectiveness Group, outside the submitted work. However, none of these relates to the topic of this submission.

Patient consent for publication Not required.

Ethics approval The OPCRD was approved by the Trent Multi-Centre Research Ethics Committee for clinical research use. This study protocol was approved by the OPCRD's Anonymised Data Ethics Protocols and Transparency Committee. There was no direct patient and public involvement (PPI) in this study, but the OPCRD was developed with PPI and is updated by a committee that includes patient representatives.

Provenance and peer review Not commissioned; externally peer reviewed.

Data availability statement Data may be obtained from a third party and are not publicly available.

Open access This is an open access article distributed in accordance with the Creative Commons Attribution 4.0 Unported (CC BY 4.0) license, which permits others to copy, redistribute, remix, transform and build upon this work for any purpose, provided the original work is properly cited, a link to the licence is given, and indication of whether changes were made. See: https://creativecommons.org/ licenses/by/4.0/.

\section{REFERENCES}

1. Murray CJL, Barber RM, Foreman KJ, et al. Global, regional, and national disability-adjusted life years (DALYs) for 306 diseases and injuries and healthy life expectancy (HALE) for 188 countries, 1990-2013: quantifying the epidemiological transition. The Lancet 2015;386:2145-91.

2. Aliberti S, Blasi F, Zanaboni AM, et al. Duration of antibiotic therapy in hospitalised patients with community-acquired pneumonia. Eur Respir J 2010;36:128-34.

3. Institute for Health Metrics and Evaluation. Global burden of disease study, 2015. Available: http://ghdx.healthdata.org/gbd-2015 [Accessed 21 Dec 2016].

4. Mathers CD, Loncar D. Projections of global mortality and burden of disease from 2002 to 2030. PLoS Med 2016;3:e442.

5. World Health Organization. Chronic obstructive pulmonary disease (COPD). WHO, 2016

6. Wedzicha JA, Seemungal TAR. Copd exacerbations: defining their cause and prevention. Lancet 2007;370:786-96.

7. Vollenweider DJ, Jarrett H, Steurer-Stey CA, et al. Antibiotics for exacerbations of chronic obstructive pulmonary disease. Cochrane database Syst Rev 2012;179.

8. Patel ISet al. Relationship between bacterial colonisation and the frequency, character, and severity of COPD exacerbations. Thorax 2002;57:759-64.

9. Seemungal T, Harper-Owen R, Bhowmik A, et al. Respiratory viruses symptoms, and inflammatory markers in acute exacerbations and stable chronic obstructive pulmonary disease. Am J Respir Crit Care Med 2001;164:1618-23.

10. Sethi S. Bacteria in exacerbations of chronic obstructive pulmonary disease: phenomenon or epiphenomenon? Proc Am Thorac Soc 2004;1:109-14.

11. Anthonisen NRet al. Antibiotic therapy in exacerbations of chronic obstructive pulmonary disease. Ann Intern Med 1987;106:196-204

12. Wedzicha JA, Miravitlles M, Hurst JR, et al. Management of COPD exacerbations: a European Respiratory Society/American Thoracic Society guideline. Eur Respir J 2017;49. 
13. Global Initiative for Chronic Obstructive Lung Disease. Pocket guide to COPD diagnosis, management and prevention - A Guide for Health Care Professionals, 2017. Available: http://goldcopd.org/ wp-content/uploads/2016/12/wms-GOLD-2017-Pocket-Guide.pdf [Accessed 23 Mar 2018].

14. World Health Organization. Global action plan on antimicrobia resistance, 2015. Available: http://www.who.int/antimicrobialresistance/publications/global-action-plan/en/ [Accessed 3 May 2015].

15. World Health Organization. Antimicrobial resistance: global report on surveillance, 2014. Available: http://www.who.int/antimicrobialresistance/publications/surveillancereport/en/ [Accessed 20 Dec 2016].

16. Ashiru-Oredope D, Sharland M, Charani E, et al. Improving the quality of antibiotic prescribing in the NHS by developing a new Antimicrobial Stewardship Programme: Start Smart--Then Focus. J Antimicrob Chemother 2012;67(Suppl 1):i51-63.

17. Public Health England. English surveillance programme for antimicrobial utilisation and resistance (ESPAUR) - Executive summary and recommendations extracted from 2016 report, 2016. Available: https://www.gov.uk/government/publications/english-surveillanceprogramme-antimicrobial-utilisation-and-resistance-espaur-report

18. Llor C, Bjerrum L, Munck A, et al. Predictors for antibiotic prescribing in patients with exacerbations of COPD in general practice. Ther Adv Respir Dis 2013;7:131-7.

19. Pouwels KB, Dolk FCK, Smith DRM, et al. Actual versus 'ideal' antibiotic prescribing for common conditions in English primary care. J Antimicrob Chemother 2018;73(suppl_2):19-26.

20. López-Campos JL, Hartl S, Pozo-Rodriguez F, et al. Antibiotic prescription for COPD exacerbations admitted to hospital: European COPD audit. PLoS One 2015;10:e0124374.

21. National Institute for Health and Clinical Excellence (NICE). Chronic obstructive pulmonary disease in over 16S: diagnosis and management. guidance and guidelines, 2010. Available: https://www.nice.org.uk/guidance/cg101/chapter/1-guidance\# management-of-exacerbations-of-copd [Accessed 13 Jan 2017].

22. Zhang H-L, Tan M, Qiu A-M, et al. Antibiotics for treatment of acute exacerbation of chronic obstructive pulmonary disease: a network meta-analysis. BMC Pulm Med 2017;17:196.

23. Herland K, Akselsen J-P, Skjønsberg $\mathrm{OH}$, et al. How representative are clinical study patients with asthma or COPD for a larger "real life" population of patients with obstructive lung disease? Respir Med 2005;99:11-19.

24. NIHR Statistics Group. NIHR statistics group annual meeting 2017. Available: https://statistics-group.nihr.ac.uk/nihr-statistics- group-annual-meeting-challenges-and-opportunities-for-appliedstatisticians/ [Accessed 8 Jan 2018].

25. New JP, Bakerly ND, Leather D, et al. Obtaining real-world evidence: the Salford lung study. Thorax 2014;69:1152-4.

26. Dolk FCK, Pouwels KB, Smith DRM, et al. Antibiotics in primary care in England: which antibiotics are prescribed and for which conditions? J Antimicrob Chemother 2018;73(suppl_2):ii2-10.

27. Boggon R, Hubbard R, Smeeth L, et al. Variability of antibiotic prescribing in patients with chronic obstructive pulmonary disease exacerbations: a cohort study. BMC Pulm Med 2013;13:32.

28. James GDR, Petersen I, Nazareth I, et al. Use of long-term antibiotic treatment in COPD patients in the UK: a retrospective cohort study. Prim Care Respir J 2013;22:271-7.

29. JSY L, Korman TM, Woolley I. Life-Long antimicrobial therapy: where is the evidence? J Antimicrob Chemother 2018;73:2601-12.

30. National Institute for Health and Clinical Excellence (NICE). Chronic obstructive pulmonary disease in over 16s: diagnosis and management, 2018. Available: https://www.nice.org.uk/guidance/ ng115/chapter/Recommendations

31. Stolbrink M, Amiry J, Blakey JD. Does antibiotic treatment duration affect the outcomes of exacerbations of asthma and COPD? A systematic review. Chron Respir Dis 2018;15:225-40.

32. Pouwels KB, Hopkins S, Llewelyn MJ, et al. Duration of antibiotic treatment for common infections in English primary care: cross sectional analysis and comparison with guidelines. BMJ 2019;73.

33. Stolbrink M, Bonnett LJ, Blakey JD. Antibiotic choice and duration associate with repeat prescriptions in infective asthma exacerbations. J Allergy Clin Immunol 2019;7:548-53.

34. Bonten MJM, Huijts SM, Bolkenbaas M, et al. Polysaccharide conjugate vaccine against pneumococcal pneumonia in adults. $N$ Engl J Med 2015;372:1114-25.

35. Miravitlles M, Cosío BG, Arnedillo A, et al. A proposal for the withdrawal of inhaled corticosteroids in the clinical practice of chronic obstructive pulmonary disease. Respir Res 2017;18:198.

36. Singh S, Loke YK. Risk of pneumonia associated with long-term use of inhaled corticosteroids in chronic obstructive pulmonary disease: a critical review and update. Curr Opin Pulm Med 2010:16:118-22.

37. Crim C, Dransfield MT, Bourbeau J, et al. Pneumonia risk with inhaled fluticasone furoate and vilanterol compared with vilanterol alone in patients with COPD. Ann Am Thorac Soc 2015;12:27-34.

38. Sykes A, Mallia P, Johnston SL. Diagnosis of pathogens in exacerbations of chronic obstructive pulmonary disease. Proc Am Thorac Soc 2007;4:642-6. 